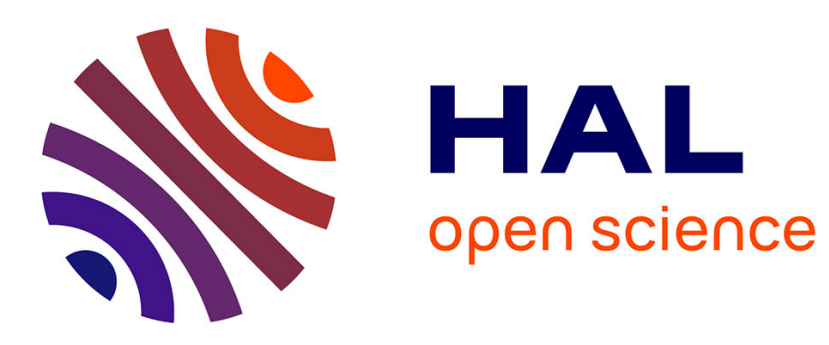

\title{
Threshold Photoelectron Spectrum of the Anilino Radical
}

Helgi Rafn Hrodmarsson, Gustavo Garcia, Laurent Nahon, Bérenger Gans, Jean-Christophe Loison

\section{To cite this version:}

Helgi Rafn Hrodmarsson, Gustavo Garcia, Laurent Nahon, Bérenger Gans, Jean-Christophe Loison. Threshold Photoelectron Spectrum of the Anilino Radical. Journal of Physical Chemistry A, 2019, 1, 10.1021/acs.jpca.9b07273 . hal-02321844

\section{HAL Id: hal-02321844 \\ https://hal.science/hal-02321844}

Submitted on 9 Nov 2020

HAL is a multi-disciplinary open access archive for the deposit and dissemination of scientific research documents, whether they are published or not. The documents may come from teaching and research institutions in France or abroad, or from public or private research centers.
L'archive ouverte pluridisciplinaire HAL, est destinée au dépôt et à la diffusion de documents scientifiques de niveau recherche, publiés ou non, émanant des établissements d'enseignement et de recherche français ou étrangers, des laboratoires publics ou privés. 


\title{
Threshold photoelectron spectrum of the anilino radical
}

\author{
Helgi Rafn Hrodmarsson**, Gustavo A. Garcia, Laurent Nahon \\ Synchrotron SOLEIL, L'Orme des Merisiers, St Aubin, BP 48, Gif sur Yvette, France \\ Bérenger Gans \\ Institut des Sciences Moléculaires d'Orsay (ISMO), UMR 8214 CNRS, Univ. Paris-Sud, \\ Université Paris-Saclay, F-91405 Orsay Cedex, France \\ Jean-Christophe Loison \\ Institut des Sciences Moléculaires (ISM), CNRS, Univ. Bordeaux, 351 cours de la Libration, \\ Talence, 33400, France
}

Total number of pages in manuscript: 13

Tables: 1

Figures: 3

Schema: 1

Running head title, if needed:

*Correspondence should be addressed to:

Helgi Rafn Hrodmarsson

Phone (HRH office): (+33) (0) 169359950

E-mail 1: helgi.hrodmarsson@synchrotron-soleil.fr

E-mail 2 : hr.hrodmarsson@gmail.com

\#Present address:

Sackler Laboratory for Astrophysics, Leiden Observatory, Leiden University, PO Box 9513, NL-2300 RA Leiden, The Netherlands 


\begin{abstract}
We report on the photoionization of the anilino radical $\left(\mathrm{C}_{6} \mathrm{H}_{5} \mathrm{NH}\right)$ formed by $\mathrm{H}$ atom abstraction from aniline by $\mathrm{F}$ atoms in a flow-tube. The spectra were recorded from 7.8 to $9.7 \mathrm{eV}$ by using a doubleimaging photoelectron-photoion coincidence spectrometer with VUV radiation provided by the DESIRS beamline at the SOLEIL synchrotron. The vibrationally-resolved recorded threshold photoelectron spectrum (TPES) of the anilino radical, exhibiting an adiabatic ionization energy of $8.02 \pm 0.02 \mathrm{eV}$, is accompanied by theoretically simulated spectra and geometry optimizations. The TPES of the aniline radical displays remarkable similarity with the threshold photoelectron spectrum of its structural isomer, 4-picolyl. This raises questions about the limitations to separating isomeric products in e.g. flame and combustion studies, with threshold photoelectron-photoion spectroscopy.
\end{abstract}

\title{
INTRODUCTION
}

Aniline (or aminobenzene) is the epitome of a prototypical aromatic amine and is of fundamental interest in terms of understanding photodissociation dynamics via $1 \pi \sigma^{*}$ states localized at amino moieties in complex heteroaromatic species. ${ }^{1}$ It has been shown that $\mathrm{N}-\mathrm{H}$ bond fission in heteroatom molecules is not only prompt ${ }^{2}$ but also an important contributor to nonradiative decay of heteroaromatics. ${ }^{3}$ The study of such nitrogen-containing aromatics in terms of their photostability and characteristics is thus axiomatically of importance not only to biophysics $^{4}$ but they have been attracting interest recently due to their role as reactive intermediates in biofuel combustion, ${ }^{5}$ coal pyrolysis, ${ }^{6}$ and astrochemistry. ${ }^{7}$

Aniline photodissociates to produce the anilino radical $\left(\mathrm{C}_{6} \mathrm{H}_{5} \mathrm{NH}\right)$ and a $\mathrm{H}$ photofragment via the $1 \pi \sigma^{*}$ state $^{8}$ which is energetically accessible at $269.513 \mathrm{~nm}(4.600 \mathrm{eV})$. The most recent experimental and theoretical efforts into studying these photodissociation dynamics of aniline have recently been succinctly summarized. ${ }^{4}$ The anilino radical (see Fig. 1) also appears as a reaction intermediate in the reaction between $N\left({ }^{2} \mathrm{D}\right)$ atoms and benzene which is of interest to chemistry in Titan's atmosphere. ${ }^{9}$ Despite the anilino radical itself appearing as a photoproduct in multiple studies of the dissociation of its parent molecule, aniline, it has been very modestly studied ${ }^{8,} 10$ and in particular to our knowledge no Photoelectron Spectrum (PES) of the neutral anilino radical has ever been reported. 


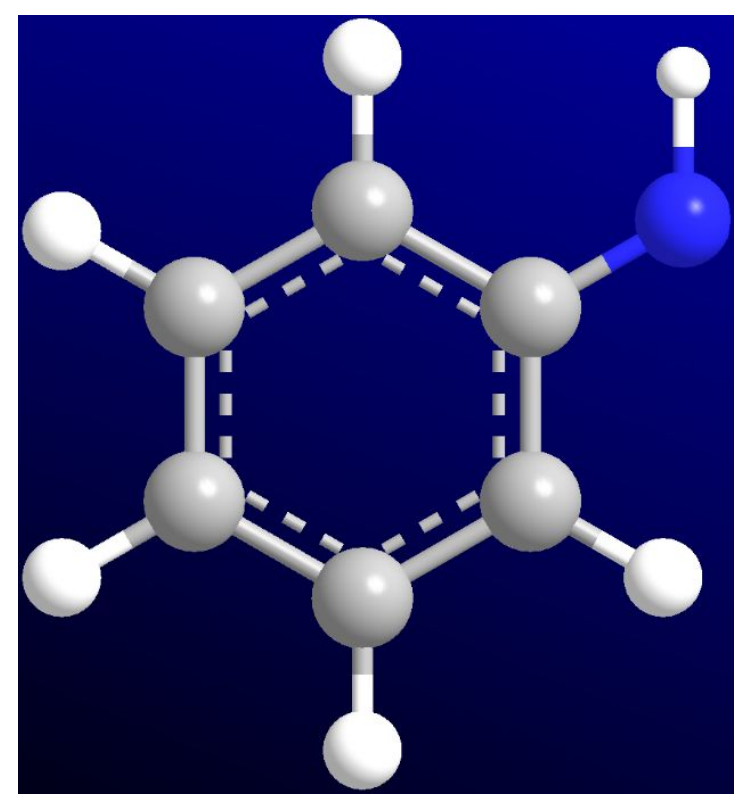

Figure 1. Molecular structure of the anilino radical, $\mathrm{C}_{6} \mathrm{H}_{5} \mathrm{NH}$. Carbon atoms are gray, hydrogen atoms white and nitrogen blue.

Apart from the neutral and cationic structural information that can be extracted by comparing experimental and theoretical photoelectron spectra, in recent years there have been successful applications of advanced mass spectrometric methods based on imaging photoelectron/photoion coincidence (i²PEICO) techniques, ${ }^{11}$ coupled to synchrotron radiation, for the study of complex chemical reactions in the gas phase. Through these coincidence schemes, the photoelectron spectrum-recorded by dispersing the energies of either the photons or the electrons ${ }^{12}$ — correlated to any peak in the time-of-flight mass spectrum can be extracted in a highly multiplex manner. Because isomers are expected to possess different vibronic structures, the photoelectron spectrum can in principle be used as a molecular fingerprint, and this has been applied to real-time, in situ species identification especially in the combustion community, ${ }^{12-13}$ but also in other types of complex chemical analyses. ${ }^{14}$ In this context, obtaining the anilino radical photoelectron fingerprint is of interest because resonantly stabilized radicals containing nitrogen can be found in both combustion chemistry and Titan's atmosphere.

Even more interesting is the fact that three additional structural isomers $\left(\mathrm{C}_{6} \mathrm{H}_{6} \mathrm{~N}\right)$, namely 2-picolyl, 3-picolyl and 4-picolyl, were recently studied in this context and their coincidence threshold photoelectron spectrum (TPES) recorded. ${ }^{15}$ All of these picolyl radicals have very similar spectral appearances but each has a distinct ionization onset thus making them easily identifiable. 
Here we present the first threshold photoelectron spectrum (TPES) of the ground state and first excited state of the cation of the anilino radical as well as the first measurement of the radical's adiabatic ionization potential. We also compare the anilino TPES spectrum to those of its picolyl isomers and discuss potential issues related to disentangling the spectra of these structural isomers.

\section{METHODS}

\section{Experimental}

Experiments were performed on the DESIRS VUV undulator beamline ${ }^{16}$ located at the third generation French national synchrotron facility SOLEIL (Gif-sur-Yvette, France). Aniline was obtained commercially (Sigma-Aldritch, $\geq 98 \%$ purity) and the anilino radical was obtained via the reaction:

$$
\mathrm{C}_{6} \mathrm{H}_{5} \mathrm{NH}_{2}+\mathrm{F} \rightarrow \mathrm{C}_{6} \mathrm{H}_{5} \mathrm{NH}+\mathrm{HF}
$$

where $\mathrm{F}$ atoms were produced from a $5 \% \mathrm{~F}_{2} / \mathrm{He}$ mixture in a $\mathrm{MW}$ discharge and injected into a flow-tube reactor ${ }^{17}$ placed inside the permanent molecular beam end-station SAPHIRS, ${ }^{18}$ while the aniline was highly diluted in He and added through a movable injector. The distance between injector and skimmer determines the reaction time, typically around $1 \mathrm{msec}$. The total pressure in the reactor was regulated at 1 torr, and the concentrations of $\mathrm{F}$ and $\mathrm{C}_{6} \mathrm{H}_{5} \mathrm{NH}_{2}$ estimated at $5.0 \times 10^{13}$ atoms $/ \mathrm{cm}^{3}$ and $1.0 \times 10^{15}$ molecules $/ \mathrm{cm}^{3}$ respectively.

The monochromator was set to deliver a photon energy resolution of $3 \mathrm{meV}$ at $8 \mathrm{eV}$. A gas filter upstream of the beamline monochromator was filled with Krypton to filter out the higher harmonics from the undulator which might be transmitted by the high orders of the monochromator's grating. We used very weak residual harmonics to our advantage by calibrating the energy scale with the ionization of Helium which is achieved by the third harmonic of the undulator at $8.1957 \mathrm{eV}$. It should be noted that the higher harmonics from the undulator are almost completely quenched (by 4 to 5 orders of magnitude) and do not impact our results. The appearance of He ionization via the third harmonic coming from the undulator is a testament to the abundance of $\mathrm{He}$ in the beam as it was the designated carrier gas for aniline and $F_{2}$ and was thus by far the largest component in the molecular beam, but its observed weak signal is not problematic for the data analysis owing to the PEPICO mass-tagging scheme.

The $\mathrm{i}^{2} \mathrm{PEPICO}$ spectrometer DELICIOUS $3^{19}$ was used to detect electrons and ions in coincidence with a velocity map imaging (VMI) setup and an imaging linear time-of-flight analyzer, respectively. Particle acceleration was achieved with a DC field of $53 \mathrm{~V} \mathrm{~cm}^{-1}$ which 
leads to a lowering of the ionization threshold by approximately $5 \mathrm{meV}$. This shift is accounted for in the energy scale calibration. Through the coincidence scheme, mass-selected photoelectron images correlated to the anilino radical $(\mathrm{m} / \mathrm{z}$ 92) having a net velocity along the molecular beam direction, as selected by defining a region of interest in the coincident ion images, were recorded in the $7.8-9.7 \mathrm{eV}$ range with $5 \mathrm{meV}$ steps. Following inversion of these images $^{20}$ the electron signal detected in coincidence with anilino ions is obtained as a function of electron kinetic energy and photon energy. In such a 2D matrix, oblique diagonal lines correspond to direct ionization to a cationic state where the kinetic energy of the produced photoelectrons increases linearly with the excess energy, $h v-I E_{i}, I E_{i}$ being the ionization energy of the $i^{\text {th }}$ state. The threshold photoelectron spectrum, or TPES, is obtained by integrating the pixel intensities along these diagonal lines up to a relatively small value of kinetic energy according to:

$$
T P E S(h v)=\int_{0}^{K E_{\text {max }}} A(h v+K E, K E) \mathrm{d} K E
$$

Where $A$ is the two-dimensional intensity matrix representing the number of coincident events as a function of photon and electron kinetic energy, and $K E_{\max }$ is the maximum kinetic energy, here $75 \mathrm{meV}$, which resulted in a full TPES resolution of $20 \mathrm{meV}$, as derived from the $3^{\text {rd }}$ order ionization of He.

This method offers a better compromise between the resolution and signal intensity when compared with how TPES are traditionally obtained, ${ }^{11}$ since more energetic electrons can be taken into account without degrading the resolution. An additional and sometimes valuable effect is the enhanced sensitivity to autoionizations. ${ }^{21}$ This also implies that the method described above can show a very poor agreement with theoretical FC-factors if on-resonance autoionizations are encountered when $K E_{\max }$ is increased. To this end, traditionally obtained TPES would be better suitable to provide better (although not perfect) fits to simulated FCfactors, but ultimately with a poorer signal-to-noise ratio.

\section{Theoretical}

The electronic structure calculations for the geometry optimization and harmonic frequencies calculations of both the neutral and the cation were carried out at DFT level (M06-2X) using the AVTZ basis set with Gaussian09. ${ }^{22}$ The adiabatic energy was obtained as the difference between their energies after correction by their zero point energy. The Franck-Condon (FC) 
factors for the photoionization of $\mathrm{C}_{6} \mathrm{H}_{5} \mathrm{NH}$ were calculated using the harmonic approximation for harmonic frequencies and normal modes in the neutral and cationic ground states, as well as the first triplet ionic state, and the Condon approximation for the dipole moment. The Duschinsky effect was considered using recursive formulae already implemented in the Gaussian09 software package. For FC calculations the rotational and vibrational temperatures were set equal to $300 \mathrm{~K}$.

\section{RESULTS AND DISCUSSION}

The 2D coincident signal as a function of electron and photon energy for the anilino radical, i.e. filtered on $m / z$ 92, is shown in Figure 2 along with the mass-selected total ion yield (TIY). Most produced photoelectrons come from direct ionization with no visible sign of autoionization process which would manifest itself by a brighter vertical line. The ground state of the cation appears to have an onset located at $8.02 \pm 0.02 \mathrm{eV}$. The TIY is reaching a plateau around $8.3 \mathrm{eV}$, marking the upper limit of the ground state, while upwards from approx. $9.0 \mathrm{eV}$ the signal becomes noisier and at slightly higher energies, namely $9.52 \pm 0.10 \mathrm{eV}$, the first excited state of the cation is observed which slightly contributes to the TIY signal increase above $9.4 \mathrm{eV}$.




Figure 2. Intensity matrix of the anilino radical (92 amu). The matrix reflects the relative number of counts of electron-ion coincidences recorded as a function of the photon energy $(x-$ axis) and the kinetic energy of the photoelectrons ( $y$-axis - left). Superimposed in white is the total ion yield which consists of the accumulated ion signals detected in coincidence as a function of photon energy. Its intensity is displayed on the right $y$-axis in arbitrary units.

The TPES recorded for $m / z 92$ is shown in Figure 3. There are two spectral signatures observed, assigned to the $\mathrm{X}^{+1} \mathrm{~A}^{\prime} \leftarrow \mathrm{X}^{2} \mathrm{~A}^{\prime \prime}$ ionizing transition to the ground state of the molecular ion, and to the $\mathrm{a}^{+} \mathrm{A}^{\prime \prime} \leftarrow \mathrm{X}^{2} \mathrm{~A}^{\prime \prime}$ transition to the first excited state. The adiabatic ionization energy is measured as $8.02 \pm 0.02 \mathrm{eV}$. The only prior measurement of the vertical ionization energy of the anilino radical was $8.23 \pm 0.1 \mathrm{eV}$ and was made by Palmer and Lossing. ${ }^{10 \mathrm{c}}$ It should be mentioned that Palmer and Lossing employed thermal decomposition of N-allyl aniline at $870^{\circ} \mathrm{C}$ to obtain anilino radicals so the higher value they obtained could be due to the presence of other isomers.

The TPES displays one hot band prior to the ionization onset, namely at $7.96 \mathrm{eV}$. The presence of hot bands is commonly observed in radicals formed by $\mathrm{H}$-abstraction by fluorine atoms since they are always very exothermic in nature due to the formation of a strong $\mathrm{H}-\mathrm{F}$ bond. ${ }^{23}$ Note that this band cannot be explained by the presence of other isomers, which would appear at higher photon energies.

The onset of the transition to the first excited state $\mathrm{a}^{+3} \mathrm{~A}^{\prime \prime} \leftarrow \mathrm{X}^{2} \mathrm{~A} "$ is recorded at $9.52 \pm$ $0.10 \mathrm{eV}$, with a higher incertitude due to the poor signal-to-noise ratio. Note that in this particular case, increasing the signal-to-noise is challenging because the energy range of interest lies above the ionization of the parent precursor, aniline $\left(\mathrm{C}_{6} \mathrm{H}_{5} \mathrm{NH}_{2}\right)$, at $7.720 \mathrm{eV},{ }^{24}$ which by far dominates the mass spectrum (See Fig. S1). 


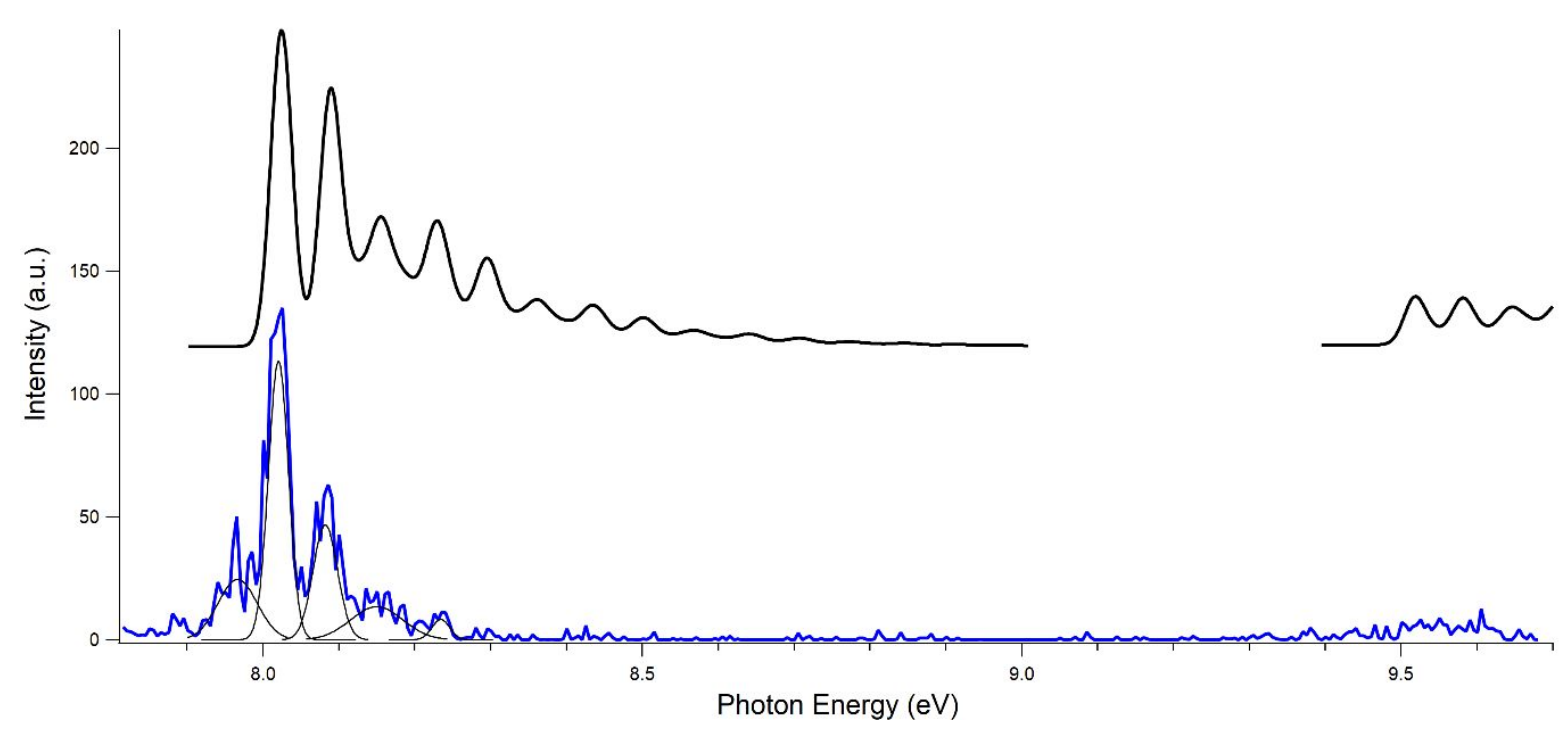

Figure 3. (Blue - bottom) TPES of the anilino radical obtained from the matrix in Figure 2. To guide the eye, superimposed on the TPES are fitted Gaussian peaks. (Black - top) Calculated TPES. The theoretical spectrum of the $\mathrm{a}^{+}{ }^{3} \mathrm{~A}$ " state has been shifted to higher energies by 0.17 $\mathrm{eV}$ to match the energy of the experiment while the theoretical spectrum of the $\mathrm{X}^{+1} \mathrm{~A}^{\prime}$ state has been shifted to lower energies by $0.02 \mathrm{eV}$.

Along with the measured TPES of anilino, Figure 3 presents its theoretical modeling. The positions of the vibrational bands match well with the calculated spectrum and we can make out the first five vibrational bands of the cation. The agreement is less satisfactory when comparing relative band ratios. As previously stated, this is a well-known feature of threshold photoelectron spectroscopy, where the presence of autoionization resonances affects the vibrational branching ratios, ${ }^{25}$ and can actually be used to reveal vibronic transitions that would have been otherwise hidden by their weak FC factors. ${ }^{21}$

Despite a weak intensity signal, the $\mathrm{a}^{+}{ }^{3} \mathrm{~A} "$ excited state is also observed in the TPES. Unfortunately, the signal is nonetheless too weak for any spectroscopic parameters to be extracted from the TPES, apart from the ionization energy.

Recently, Reusch et al. ${ }^{15}$ published the TPES of three structural isomers of the anilino radical, namely the picolyl radicals. Out of the three picolyl radicals, the 4-picolyl radical was found to exhibit a TPES almost exactly resembling that of the TPES of the anilino radical in terms of peak positions, and ionization energy. In their SI, Reusch et al. ${ }^{15}$ included an experimental spectrum up to $10.0 \mathrm{eV}$ which showed a broad and unstructured band with a maximum around $9.5 \mathrm{eV}$. They commented that this band contained transitions into excited electronic states of the cation, particularly the lowest triplet state which they computed at 9.08 
eV. Meanwhile, our TPES finds the $\mathrm{a}^{+3} \mathrm{~A}^{\prime}$ excited state at $9.52 \mathrm{eV}$ whilst computations placed it at $9.35 \mathrm{eV}$. It is thus unclear at present whether the excited states could be utilized to disentangle the anilino and 4-picolyls in a TPES of a complex mixture.

Palmer and Lossing ${ }^{10 \mathrm{c}}$ already performed a comparison of ionization energies between the four isomers and found that substitution of $\mathrm{CH}$ for $\mathrm{N}$ had the largest effect on the para position, i.e. for the 4-picolyl radical, which is exactly the opposite of what we observe here. Indeed, the adiabatic ionization energies of anilino and 4-picolyl radicals are the same within the error bars, whereas the 2- and 3-picolyl radicals have noticeably lower IEs. This was rationalized by Reusch et al. in terms of charge delocalization. In the case of 4- and 2-picolyl radicals, there is always a resonant structure that places the positive charge in the electrophilic $\mathrm{N}$ atom, while there is no such a structure for the meta 3-picolyl radical, which confers it more stability in the cation, lowering the ionization energy. The largest positive charge on the $\mathrm{N}$ atom was found for the 4-picolyl, and was given as the reason for the $\sim 300 \mathrm{meV}$ shift to a higher ionization energy. As shown in Schema 1, the anilino radical also has a resonant structure where the charge is placed in the $\mathrm{N}$ atom, lowering the cation stability and increasing its ionization energy so that it matches that of 4-picolyl.

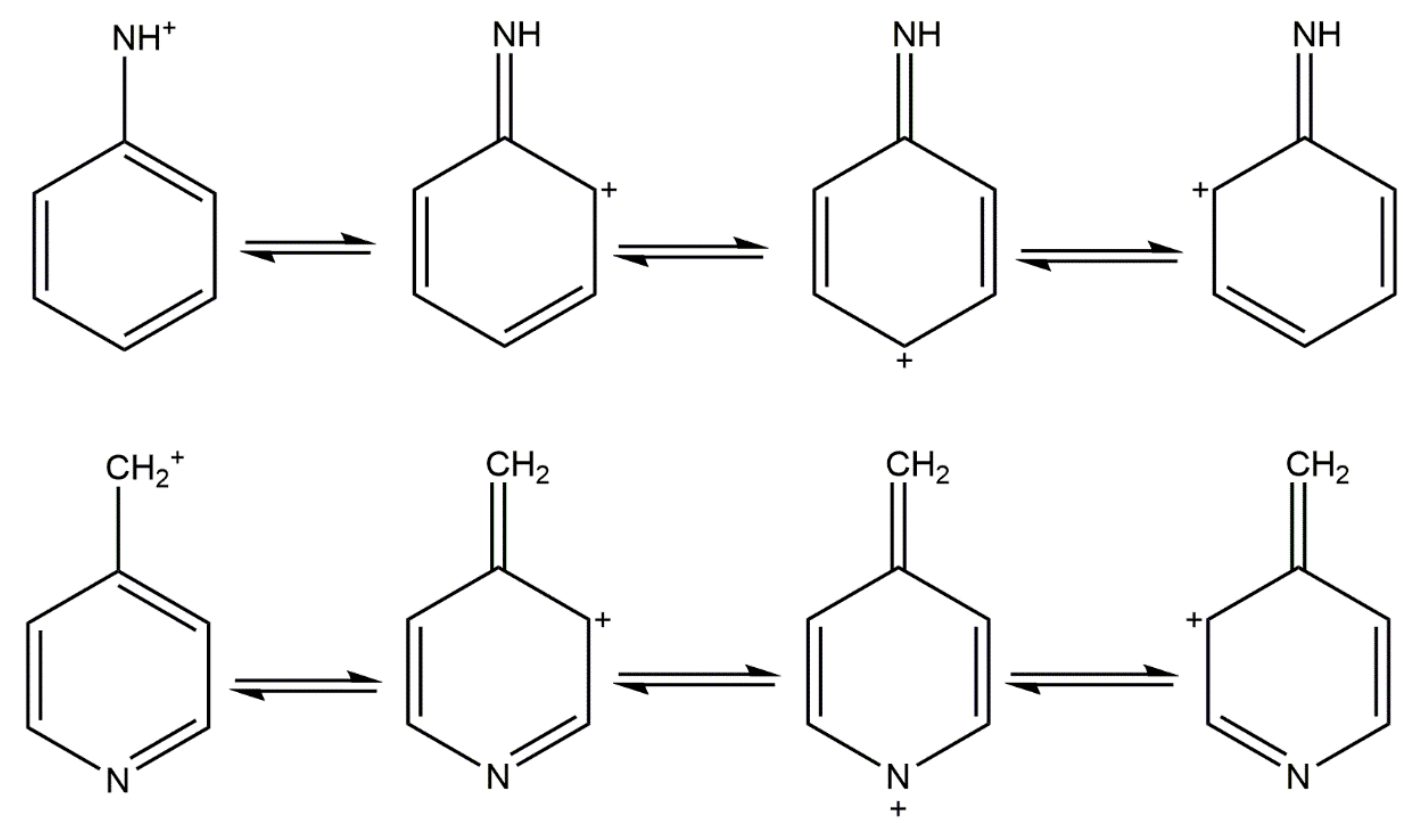

Schema 1: Charge resonant structures of anilino (top) and 4-picolyl (bottom) radicals.

Additionally, the four isomers have similar vibrational progressions (see Table 1), arising solely from the in-plane deformation mode of the ring, $v_{29}^{+}$, in line with the geometry changes upon ionization. Indeed, upon ionization of both anilino and picolyl radicals, the most 
significant bond contraction takes place between the external moieties (-NH and $-\mathrm{CH}_{2}$, respectively) and the aromatic ring (see Table S1 of the SI for the calculated anilino neutral and cationic geometries). In addition, in all four isomers the ring atoms undergo a rearrangement that leads to the excitation of the same in-plane deformation mode, $v_{29}^{+}$, shown in Figure $\mathrm{S} 2$ of the SI for the anilino cation. As for the ionization energies, the mode frequencies are equal within the experimental error bars in the case of anilino and 4-picolyl radicals.

Table 1. Ionization energy, computed ionization energy and the vibrational progression of the anilino radical in comparison with those of the picolyl radicals obtained by Reusch et al. ${ }^{15}$

\begin{tabular}{|l|l|l|l|}
\hline & Ionization energy $(\mathrm{eV})$ & Computed values & $v \underset{\exp }{+}\left(\mathrm{cm}^{-1}\right)$ \\
\hline Anilino & $8.02 \pm 0.02$ & 8.03 & 530 \\
\hline 4-Picolyl & $8.01 \pm 0.01$ & 8.06 & 530 \\
\hline 3-Picolyl & $7.59 \pm 0.01$ & 7.65 & 560 \\
\hline 2-Picolyl & $7.70 \pm 0.02$ & 7.73 & 520 \\
\hline
\end{tabular}

\section{CONCLUSION}

We have presented and discussed the threshold photoelectron spectrum of the anilino radical. The anilino radical was produced via hydrogen abstraction of an aniline precursor with fluorine atoms obtained from flowing molecular fluorine through a microwave discharge. The spectrum shows a clear adiabatic transition, with a prominent (0-0) origin band, followed by a progression on the in-plane deformation mode, as in the case of the benzy $1^{26}$ or picolyl ${ }^{15}$ radicals, assigned by comparison to a simulated photoelectron spectrum.

Interestingly, the TPES of anilino and one of its structural isomers, 4-picolyl, are effectively identical within the experimental error. In recent years, the TPES technique has been implemented in isomer separation of the products of mixed flames. ${ }^{12-13}$ The crux of that technique working is that each individual molecule has a unique electronic fingerprint in the form of a (threshold) photoelectron spectrum. Our recorded spectrum of the anilino radical represents the first recorded instance of two isomers having the exact same spectral fingerprint and hence other considerations would have to be taken into account to disentangle these two radical species, such as vibronic structures of the cationic excited states, state-selected fragmentation patterns or an a-priori chemical knowledge of the expected species. 


\section{ACKNOWLEDGMENTS}

We are grateful to the whole SOLEIL for provision of synchrotron radiation under proposal number 99180002, as well as to J.-F. Gil for his technical assistance on the SAPHIRS endstation. This work received financial support from the French Agence Nationale de la Recherche (ANR) under grant ANR-12-BS08-0020-02 (project SYNCHROKIN).

\section{REFERENCES}

1. Roberts, G. M.; Stavros, V. G., The role of pi sigma* states in the photochemistry of heteroaromatic biomolecules and their subunits: insights from gas-phase femtosecond spectroscopy. Chem. Sci. 2014, 5 (5), 1698-1722.

2. Ashfold, M. N. R.; Cronin, B.; Devine, A. L.; Dixon, R. N.; Nix, M. G. D., The role of pi sigma* excited states in the photodissociation of heteroaromatic molecules. Science 2006, 312 (5780), 1637-1640.

3. Sobolewski, A. L.; Domcke, W.; Dedonder-Lardeux, C.; Jouvet, C., Excited-state hydrogen detachment and hydrogen transfer driven by repulsive (1)pi sigma* states: A new paradigm for nonradiative decay in aromatic biomolecules. Phys. Chem. Chem. Phys. 2002, 4 (7), 1093-1100.

4. Ray, J.; Ramesh, S. G., Conical intersections involving the lowest (1)pi sigma* state in aniline: Role of the NH2 group. Chem. Phys. 2018, 515, 77-87.

5. Kohse-Hoinghaus, K.; Osswald, P.; Cool, T. A.; Kasper, T.; Hansen, N.; Qi, F.; Westbrook, C. K.; Westmoreland, P. R., Biofuel Combustion Chemistry: From Ethanol to Biodiesel. Angew. Chem.-Int. Edit. 2010, 49 (21), 3572-3597.

6. Glarborg, P.; Jensen, A. D.; Johnsson, J. E., Fuel nitrogen conversion in solid fuel fired systems. Prog. Energy Combust. Sci. 2003, 29 (2), 89-113.

7. Parker, D. S. N.; Kaiser, R. I., On the formation of nitrogen-substituted polycyclic aromatic hydrocarbons (NPAHs) in circumstellar and interstellar environments. Chem. Soc. Rev. 2017, 46 (2), 452-463.

8. King, G. A.; Oliver, T. A. A.; Ashfold, M. N. R., Dynamical insights into (1)pi sigma* state mediated photodissociation of aniline. J. Chem. Phys. 2010, 132 (21), 12.

9. (a) Balucani, N., Pacifici, L., Skouteris, D., Caracciolo, A., Casavecchia, P., Falcinelli, S., Rosi, M., A Computational Study of the Reaction N(2D) + C6H6 Leading to Pyridine and Phenylnitrene. In Computational Science and Its Applications - ICCSA 2018, 1 ed.; Misra, S. e. a., Ed. Springer International Publishing: 2019; (b) Balucani, N., Pacifici, L., Skouteris, D., Caracciolo, A., Casavecchia, P., Falcinelli, S., Rosi, M., A Theoretical Investigation of the Reaction N(2D) + C6H6 and Implications for the Upper Atmosphere of Titan. In Computational Science and Its Applications - ICCSA 2018, 1 ed.; Misra, S. e. a., Ed. Springer International Publishing: 2019.

10. (a) Porter, G.; Wright, F. J., Primary Photochemical Processes in Aromatic Molecules 3. Absorption Spectra of Benzyl, Anilino, Phenoxy and Related Free Radicals. Transactions of the Faraday Society 1955, 51 (11), 1469-\&; (b) Norman, I.; Porter, G., Trapped Atoms and Radicals in Rigid Solvents. Proceedings of the Royal Society of London Series a-Mathematical and Physical Sciences 1955, 230 (1182), 399-\&; (c) Palmer, T. F.; Lossing, F. P., Free Radicals by Mass Spectrometry 30. Ionilinenization Potentials of Anilino and 2-, 3- and 4-Pyridylmethyl Radicals. J. Am. Chem. Soc. 1963, 85 (12), 1733-\&; (d) Land, E. J.; Porter, G., Primary Photochemical Processes in Aromatic Molecules 8. Absorption Spectra and Acidity Constants of Anilino Radicals. Transactions of the Faraday Society 1963, 59 (489), 2027-\&; (e) McMillen, D. F.; Golden, D. M., Hydrocarbson Bond-Dissociation Energies. Annu. Rev. Phys. 
Chem. 1982, 33, 493-532; (f) Drzaic, P. S.; Brauman, J. I., Electron Photodetachment from Phenylnitrene, Anilide, and Benzyl Anions - Electron-Affinities of the Anilino and Benzyl Radicals and Phenylnitrene. J. Phys. Chem. 1984, 88 (22), 5285-5290; (g) Tripathi, G. N. R.; Schuler, R. H., Time Resolved Resonance Raman-Spectra of Anilino Radical and Aniline Radical Cation. J. Chem. Phys. 1987, 86 (7), 3795-3800; (h) Wren, S. W.; Vogelhuber, K. M.; Ichino, T.; Stanton, J. F.; Lineberger, W. C., Photoelectron Spectroscopy of Anilinide and Acidity of Aniline. J. Phys. Chem. A 2012, 116 (12), 3118-3123.

11. Baer, T.; Tuckett, R. P., Advances in threshold photoelectron spectroscopy (TPES) and threshold photoelectron photoion coincidence (TPEPICO). Phys Chem Chem Phys 2017, 19 (15), 9698-9723.

12. Kruger, J.; Garcia, G. A.; Felsmann, D.; Moshammer, K.; Lackner, A.; Brockhinke, A.; Nahon, L.; Kohse-Hoinghaus, K., Photoelectron-photoion coincidence spectroscopy for multiplexed detection of intermediate species in a flame. Phys Chem Chem Phys 2014, 16 (41), 22791-804.

13. (a) Felsmann, D.; Lucassen, A.; Kruger, J.; Hemken, C.; Tran, L. S.; Pieper, J.; Garcia, G. A.; Brockhinke, A.; Nahon, L.; Kohse-Hoinghaus, K., Progress in Fixed-Photon-Energy Time-Efficient Double Imaging Photoelectron/Photoion Coincidence Measurements in Quantitative Flame Analysis. Z. Phys. Chemie-Int. J. Res. Phys. Chem. Chem. Phys. 2016, 230 (8), 1067-1097; (b) Pieper, J.; Schmitt, S.; Hemken, C.; Davies, E.; Wullenkord, J.; Brockhinke, A.; Kruger, J.; Garcia, G. A.; Nahon, L.; Lucassen, A.; Eisfeld, W.; Kohse-Hoinghaus, K., Isomer Identification in Flames with DoubleImaging Photoelectron/Photoion Coincidence Spectroscopy (i(2)PEPICO) using Measured and Calculated Reference Photoelectron Spectra. Z. Phys. Chemie-Int. J. Res. Phys. Chem. Chem. Phys. 2018, 232 (2), 153-187; (c) Bodi, A.; Hemberger, P.; Osborn, D. L.; Sztaray, B., Mass-Resolved Isomer-Selective Chemical Analysis with Imaging Photoelectron Photoion Coincidence Spectroscopy. J. Phys. Chem. Lett. 2013, 4 (17), 2948-2952; (d) Osswald, P.; Hemberger, P.; Bierkandt, T.; Akyildiz, E.; Kohler, M.; Bodi, A.; Gerber, T.; Kasper, T., In situ flame chemistry tracing by imaging photoelectron photoion coincidence spectroscopy. Rev. Sci. Instrum. 2014, 85 (2), 11.

14. (a) Cunha de Miranda, B.; Garcia, G. A.; Gaie-Levrel, F.; Mahjoub, A.; Gautier, T.; Fleury, B.; Nahon, L.; Pernot, P.; Carrasco, N., Molecular Isomer Identification of Titan's Tholins Organic Aerosols by Photoelectron/Photoion Coincidence Spectroscopy Coupled to VUV Synchrotron Radiation. J Phys Chem A 2016, 120 (33), 6529-40; (b) Baeza-Romero, M. T.; Gaie-Levrel, F.; Mahjoub, A.; López-Arza, V.; Garcia, G. A.; Nahon, L., A smog chamber study coupling a photoionization aerosol electron/ion spectrometer to VUV synchrotron radiation: organic and inorganic-organic mixed aerosol analysis. The European Physical Journal D 2016, 70 (7).

15. Reusch, E.; Holzmeier, F.; Constantinidis, P.; Hemberger, P.; Fischer, I., IsomerSelective Generation and Spectroscopic Characterization of Picolyl Radicals. Angew. Chem.Int. Edit. 2017, 56 (27), 8000-8003.

16. Nahon, L.; de Oliveira, N.; Garcia, G. A.; Gil, J. F.; Pilette, B.; Marcouille, O.; Lagarde, B.; Polack, F., DESIRS: a state-of-the-art VUV beamline featuring high resolution and variable polarization for spectroscopy and dichroism at SOLEIL. J. Synchrot. Radiat. 2012, 19, 508520 .

17. Garcia, G. A.; Tang, X. F.; Gil, J. F.; Nahon, L.; Ward, M.; Batut, S.; Fittschen, C.; Taatjes, C. A.; Osborn, D. L.; Loison, J. C., Synchrotron-based double imaging photoelectron/photoion coincidence spectroscopy of radicals produced in a flow tube: $\mathrm{OH}$ and OD. J. Chem. Phys. 2015, 142 (16), 8.

18. Tang, X. F.; Garcia, G. A.; Gil, J. F.; Nahon, L., Vacuum upgrade and enhanced performances of the double imaging electron/ion coincidence end-station at the vacuum ultraviolet beamline DESIRS. Rev. Sci. Instrum. 2015, 86 (12), 8. 
19. Garcia, G. A.; de Miranda, B. K. C.; Tia, M.; Daly, S.; Nahon, L., DELICIOUS III: A multipurpose double imaging particle coincidence spectrometer for gas phase vacuum ultraviolet photodynamics studies. Rev. Sci. Instrum. 2013, 84 (5), 11.

20. Garcia, G. A.; Nahon, L.; Powis, I., Two-dimensional charged particle image inversion using a polar basis function expansion. Review of Scientific Instruments 2004, 75 (11), 49894996.

21. Briant, M.; Poisson, L.; Hochlaf, M.; de Pujo, P.; Gaveau, M. A.; Soep, B., Ar-2 Photoelectron Spectroscopy Mediated by Autoionizing States. Phys. Rev. Lett. 2012, 109 (19), 5 .

22. Gaussian 09, R. A., Frisch, M. J.; Trucks, G. W.; Schlegel, H. B.; Scuseria, G. E.; Robb, M. A.; Cheeseman, J. R.; Scalmani, G.; Barone, V.; Mennucci, B.; Petersson, G. A.; Nakatsuji, H.; Caricato, M.; Li, X.; Hratchian, H. P.; Izmaylov, A. F.; Bloino, J.; Zheng, G.; Sonnenberg, J. L.; Hada, M.; Ehara, M.; Toyota, K.; Fukuda, R.; Hasegawa, J.; Ishida, M.; Nakajima, T.; Honda, Y.; Kitao, O.; Nakai, H.; Vreven, T.; Montgomery, Jr., J. A.; Peralta, J. E.; Ogliaro, F.; Bearpark, M.; Heyd, J. J.; Brothers, E.; Kudin, K. N.; Staroverov, V. N.; Kobayashi, R.; Normand, J.; Raghavachari, K.; Rendell, A.; Burant, J. C.; Iyengar, S. S.; Tomasi, J.; Cossi, M.; Rega, N.; Millam, N. J.; Klene, M.; Knox, J. E.; Cross, J. B.; Bakken, V.; Adamo, C.; Jaramillo, J.; Gomperts, R.; Stratmann, R. E.; Yazyev, O.; Austin, A. J.; Cammi, R.; Pomelli, C.; Ochterski, J. W.; Martin, R. L.; Morokuma, K.; Zakrzewski, V. G.; Voth, G. A.; Salvador, P.; Dannenberg, J. J.; Dapprich, S.; Daniels, A. D.; Farkas, Ö.; Foresman, J. B.; Ortiz, J. V.; Cioslowski, J.; Fox, D. J. , Gaussian, Inc., Wallingford CT, 2009.

23. Williams, R. L.; Rowland, F. S., Hydrogen-Atom Abstraction by Fluorine Atomas. $J$. Phys. Chem. 1973, 77 (3), 301-307.

24. Hager, J.; Smith, M. A.; Wallace, S. C., Auto-Ionizing Rydberg Structure Observed in the Vibrationally Selective, 2-Color, Threshold Photoionization Spectrum of Jet-Cooled Aniline. J. Chem. Phys. 1985, 83 (9), 4820-4822.

25. Baer, T.; Guyon, P.-M., An Historical Introduction to Threshold Photoionization. In High Resolution Laser Photoionization and Photoelectron Studies, I. Powis, T. B., C. Ng, Ed. John Wiley \& Sons: Chichester, U.K., 1995; p 1.

26. Savee, J. D.; Zador, J.; Hemberger, P.; Sztaray, B.; Bodi, A.; Osborn, D. L., Threshold photoelectron spectrum of the benzyl radical. Mol. Phys. 2015, 113 (15-16), 2217-2227. 


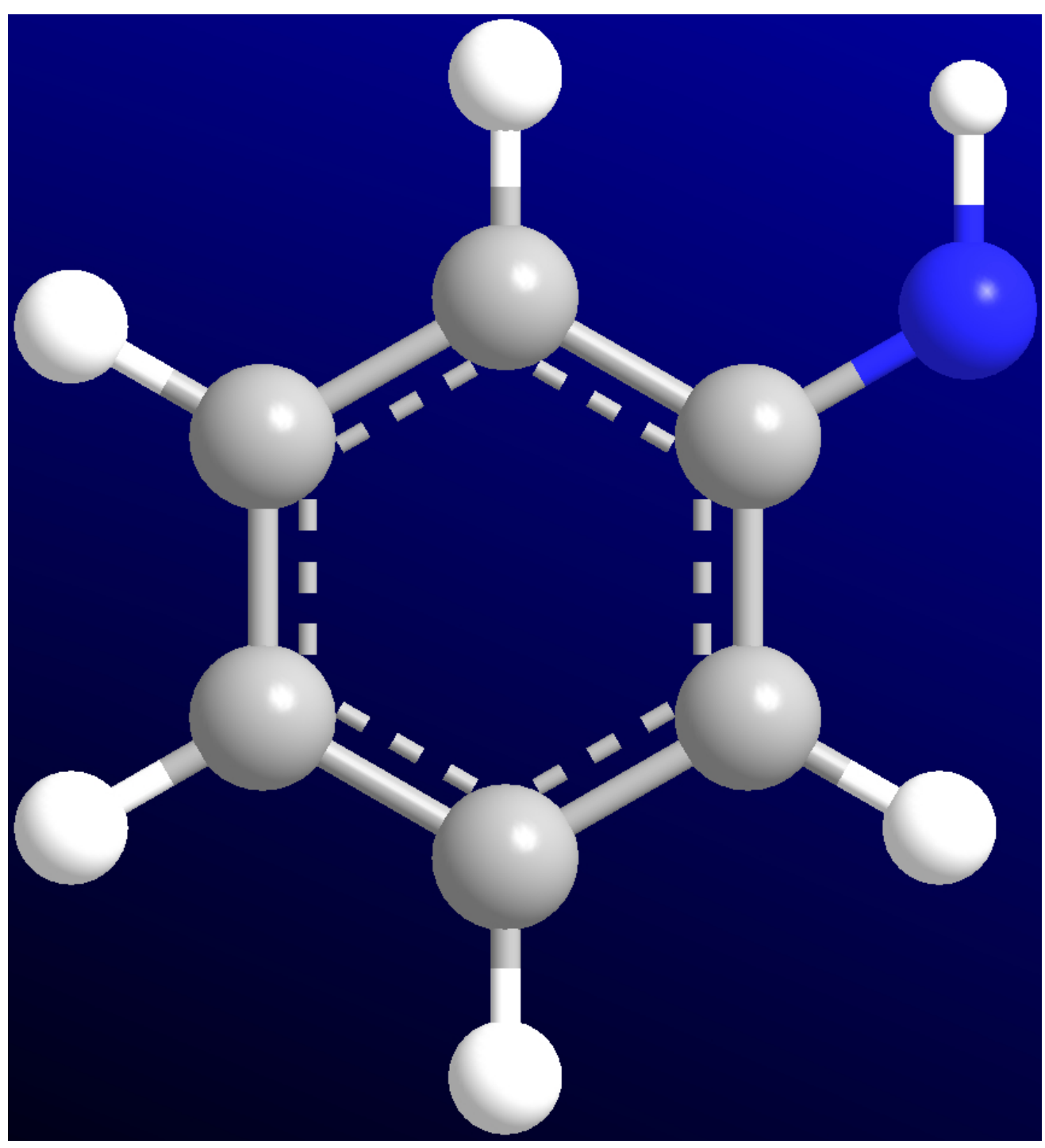

Molecular structure of the anilino radical, $\mathrm{C} 6 \mathrm{H} 5 \mathrm{NH}$. Carbon atoms are gray, hydrogen atoms white and nitrogen blue.

\section{$72 \times 79 \mathrm{~mm}(300 \times 300 \mathrm{DPI})$}




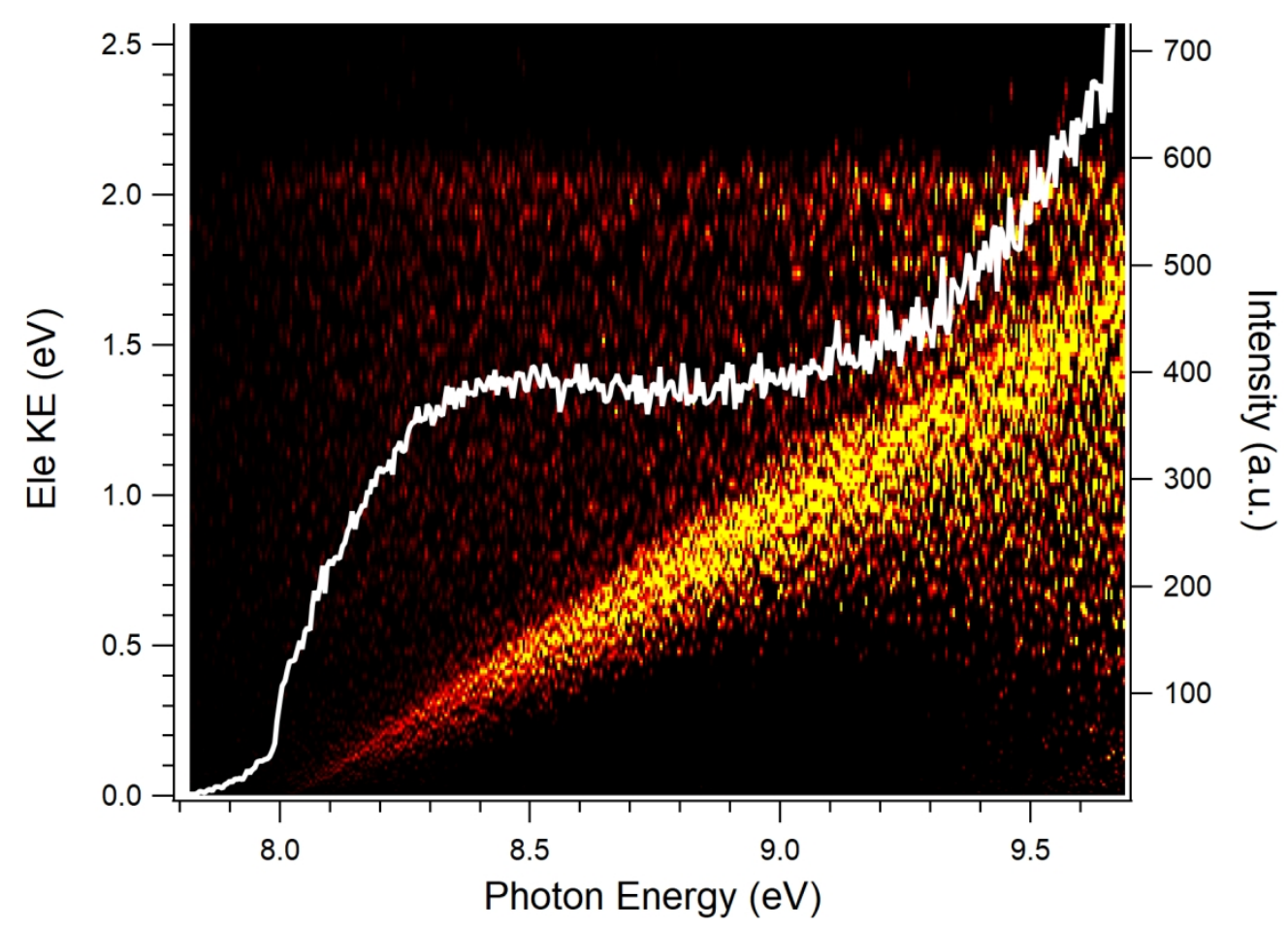

Intensity matrix of the anilino radical (92 amu). The matrix reflects the relative number of counts of electron-ion coincidences recorded as a function of the photon energy (x-axis) and the kinetic energy of the photoelectrons ( $y$-axis - left). Superimposed in white is the total ion yield which consists of the accumulated ion signals detected in coincidence as a function of photon energy. Its intensity is displayed on the right $y$ axis in arbitrary units. 


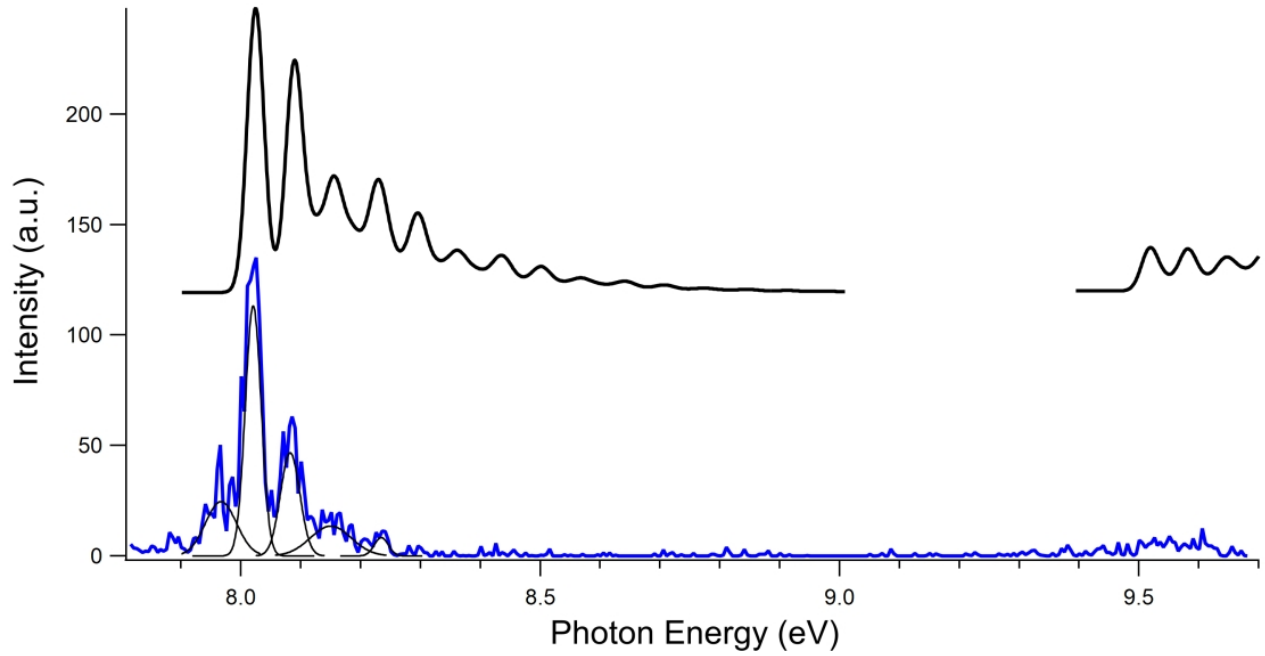

(Blue - bottom) TPES of the anilino radical obtained from the matrix in Figure 2. To guide the eye, superimposed on the TPES are fitted Gaussian peaks. (Black - top) Calculated TPES. The theoretical spectrum of the $a+3 A^{\prime \prime}$ state has been shifted to higher energies by $0.17 \mathrm{eV}$ to match the energy of the experiment while the theoretical spectrum of the $X+1 A^{\prime}$ state has been shifted to lower energies by 0.02 eV. 

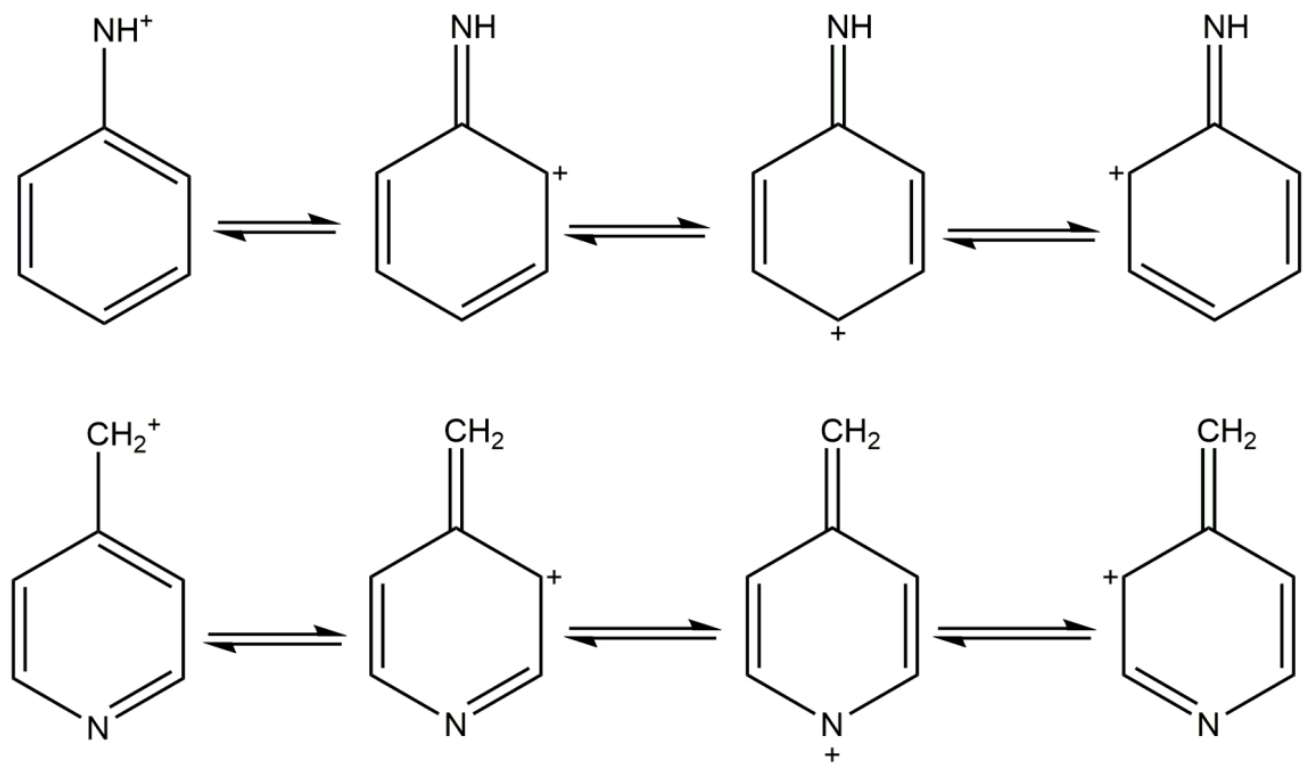

Charge resonant structures of anilino (top) and 4-picolyl (bottom) radicals.

$140 \times 82 \mathrm{~mm}(300 \times 300 \mathrm{DPI})$ 
TOF mass spectrum for the $\mathrm{C} 6 \mathrm{H} 5 \mathrm{NH} 2+\mathrm{F}$ flow-tube reaction. The strongest signal corresponds to the anilino parent ion ( $\mathrm{m} / \mathrm{z}$ 93) with the signal of the anilino radical $(\mathrm{m} / \mathrm{z} 92)$ being approx. 10x weaker. Peaks are also observed at $\mathrm{m} / \mathrm{z} 111$ and $\mathrm{m} / \mathrm{z} 112$ which correspond to the addition of a $\mathrm{F}$ atom to anilino and aniline, respectively. The peak at $\mathrm{m} / \mathrm{z} 94$ corresponds to the $13 \mathrm{C}$ contribution from the precursor main peak ( $\mathrm{m} / \mathrm{z}$ 93).

$251 \times 115 \mathrm{~mm}(600 \times 600 \mathrm{DPI})$ 


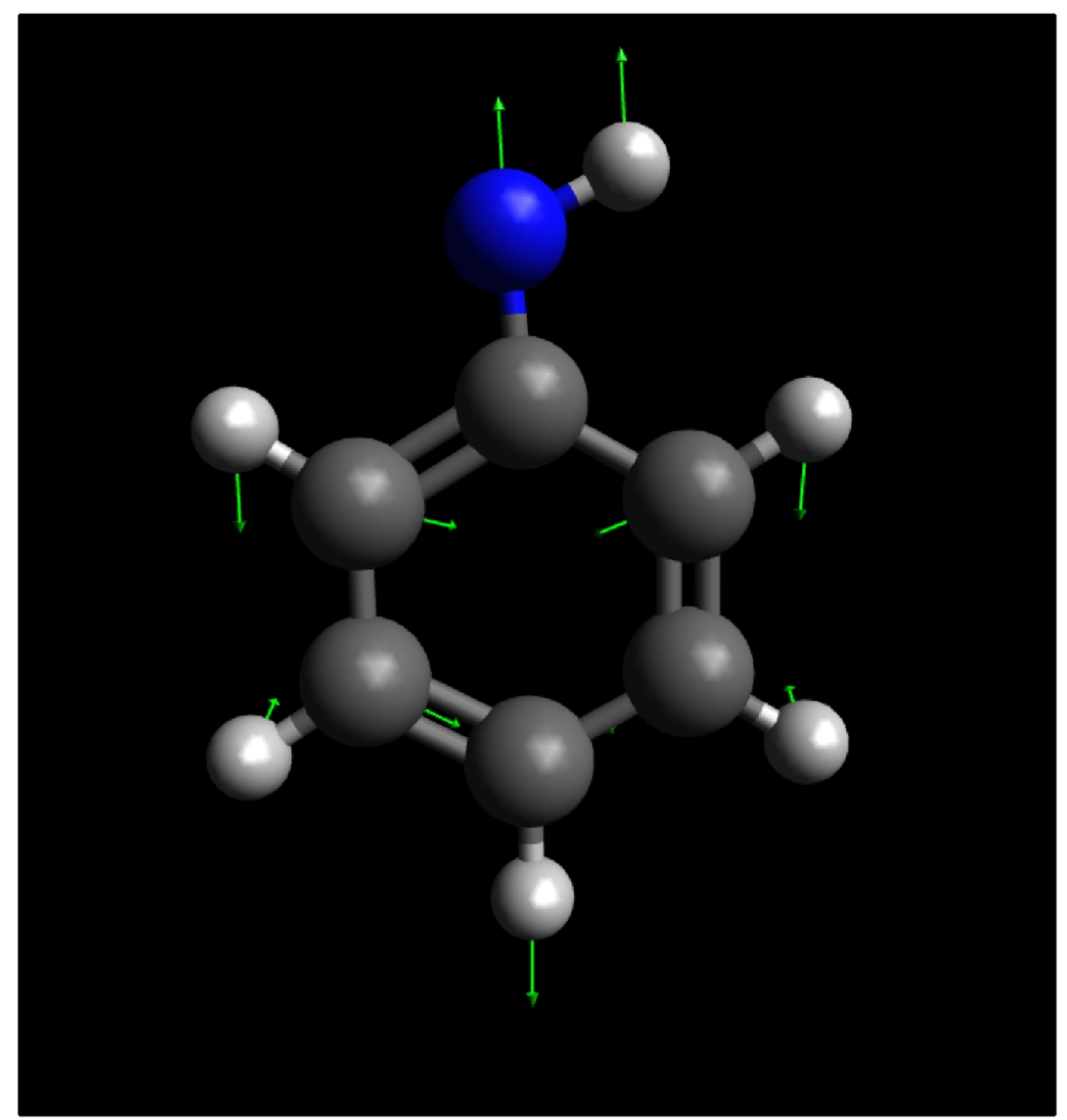

Illustration of the in-plane deformation mode, $v \_29^{\wedge}+$. Vibrational frequencies are computed by computed at DFT level (M06-2X) using the AVTZ basis set with Guassian09. 